\title{
Anthelmintic resistance in sheep gastrointestinal nematodes in Slovakia detected by in-vitro methods
}

\author{
Michaela Dolinská1, Oksana Ivanišinová ${ }^{2}$ Alžbeta Königová ${ }^{1}$ and Marián Várady ${ }^{1 *}$
}

\begin{abstract}
Background: The intensive use of anthelmintics for the control of helminthic infections has resulted in the development of anthelmintic resistance, which has become a major practical problem in many countries. A variety of tests are available to monitor anthelmintic resistance but most of them are expensive, laborious and time consuming and therefore unpractical for large field surveys. The main aim of this survey was thus to detect the occurrence of benzimidazole (BZ) and macrocyclic lactone resistance on sheep farms in Slovakia by using novel and modified in vitro methods that are inexpensive, easy to use and quick and therefore practical for large surveys.

Results: BZ-resistant gastrointestinal nematodes were found on all 27 farms. Two farms (7.4\%) had high levels of resistance ( $>40 \%$ of hatching), and 22 farms had low levels ( $<20 \%$ of hatching) of resistant nematodes. IVM-resistant populations were found on 14 of 49 sheep farms. The prevalence of BZ and IVM resistance has slightly increased on Slovak sheep farms during the last two decades.

Conclusions: Both the BZ and IVM surveys indicated that resistance against anthelmintics was present on Slovak sheep farms. Resistance against the BZ class of anthelmintics had been stable for two decades, but a slight increase on IVM resistance was confirmed. Farmers must thus observe the preventive measures to avoid a faster onset of IVM resistance, otherwise the presence of resistant parasites and ineffective treatment may harm the economy of their farms.
\end{abstract}

Keywords: Anthelmintic resistance, Sheep nematodes, Egg hatch test, Larval development test

\section{Background}

Resistance to anthelmintic compounds in gastrointestinal parasites of sheep is presently cosmopolitan, and single- and multiple-drug resistant species are common throughout the world [1]. The reports of anthelmintic resistance (AR) in European countries mainly concern resistance against benzimidazoles (BZs), with local reports of levamisole resistance and isolated cases of resistance to macrocyclic lactones (MLs) [2,3]. BZ resistance has notably not yet reached a critical level in some European countries, e.g. Greece [4], Spain [5], Sweden [6], Italy [7] and Slovakia [8]. The extent and significance of AR in sheep in Slovakia have been previously studied in two national surveys. BZ resistance in Slovakia was first

\footnotetext{
*Correspondence: varady@saske.sk

'Institute of Parasitology, Slovak Academy of Sciences, Hlinkova 3, Košice 040 01, Slovak Republic

Full list of author information is available at the end of the article
}

investigated in a survey in 1991-1993 [9]. This survey examined 77 farms and documented the presence of $\mathrm{BZ}$ resistance on six (7.8\%) of the farms by using an in vitro egg hatch test (EHT). A survey in 2003-2004 [8,10] identified resistance to BZs on two of 29 farms (6.9\%) by using a feacal egg count reduction (FECR) test, an in vitro EHT and a larval development test. Assuming that a low prevalence of $\mathrm{BZ}$ resistance persisted continuously between these two surveys, the status of BZ resistance appears not to have changed on Slovak sheep farms during that decade. The current extent of ivermectin (IVM) resistance in sheep parasites in the Slovak Republic is not known. Only one survey, in 2003-2004, covering 26 sheep farms has been conducted [8]. Resistance to IVM was suspected on eight of these farms (30.8\%).

The growing importance of AR has led to an increased need for reliable and standardized methods of detection 
[11-13]. Effective monitoring of resistance is vital for maintaining a high efficacy of the currently available anthelmintics and for preventing further selection for resistance, especially in areas where AR is present in only a small proportion of the worm population. The use of a discrimination/delineating dose (DD) in the EHT provides a good estimate of genotypic resistance [14]. The egg hatch discrimination dose test (EHDDT) is less time-consuming, allows the reliable detection of a frequency of resistance alleles below $10 \%$ and is fairly reliable for the detection of BZ resistance under field conditions [14]. The micro-agar larval development test (MALDT) for detecting IVM resistance provides comparable and reliable results and can detect low proportions of resistant worms in populations, a sensitivity that should have potential in determining resistance with field tests $[15,16]$.

The most commonly used drugs in Slovakia have been $\mathrm{BZ}$ and ML anthelmintics [17]. The main aim of this survey was thus to detect the occurrence of $\mathrm{BZ}$ and $\mathrm{ML}$ resistance on sheep farms in Slovakia by using novel and modified in vitro methods that are inexpensive, easy to use and quick and therefore practical for large surveys.

\section{Methods}

\section{Trial design}

Animal use and study design were approved by the Ethics Committee of the Institute of Parasitology of the Slovak Academy of Sciences in accordance with the national legislation in Slovakia - Animal Welfare Act No. 23/2009. Forty-nine sheep farms were investigated in 17 districts in Slovakia. Permission to collect study samples was granted by all participating sheep farms. The sheep flocks consisted of 300-800 animals on each farm. The farms mainly kept Tsigaja, Improved Valachian and Merino breeds. The animals examined were lambs or yearlings that had not received any anthelmintic treatment for at least 10 weeks before the initiation of the tests. On each farm, 15-20 animals were selected, and fecal samples were collected directly from the rectum. Pooled fecal samples weighing 50-100 g were stored anaerobically at room temperature [18] and processed within a maximum of two days. Nematode eggs were collected by sequentially sieving the faeces through three stacked sieves with decreasing apertures of 250, 100 and $20 \mu \mathrm{m}$. The material collected on the $20-\mu \mathrm{m}$ sieve was washed with tap water and sedimented, after which the trichostrongylid eggs were recovered by the salt flotation method [19] and used for in vitro EHDDTs and MALDTs.

\section{Egg hatch discrimination dose test}

The EHDDT was performed as described by Coles et al. [20]. A stock solution of thiabendazole (TBZ) (SigmaAldrich, Germany) was prepared by dissolving the pure compound in dimethyl sulfoxide (DMSO). The final concentration was prepared by adding $10 \mu \mathrm{l}$ of the TBZ solution to $1.99 \mathrm{ml}$ of an aqueous suspension of approximately 150 eggs $\cdot \mathrm{ml}^{-1}$. A single TBZ concentration of $0.1 \mu \mathrm{g} \cdot \mathrm{ml}^{-1}$ was used. A control (0.5\% DMSO) without anthelmintic was also included in the test. The dosed egg suspensions were incubated in 24-well plates (Nuncleon, Denmark) for $48 \mathrm{~h}$ at $27^{\circ} \mathrm{C}$. The incubation was then terminated by adding $10 \mu \mathrm{l}$ of Lugol's iodine to each well, and the numbers of eggs and larvae were counted. The test was performed with two replicates.

\section{Micro-agar larval development test}

We used the method described by Coles et al. [13]. Tests were performed in 96-well microtiter plates. As we demonstrated in our previous study, the use of avermectin analogs and especially IVM aglycone significantly increased the ability of the test to differentiate between IVM-resistant and -susceptible isolates [15,16]. Stock drug solutions of IVM aglycone (Tebu-bio, France) with concentration of $13,02 \mu \mathrm{g} . \mathrm{ml}^{-1}$ were serially diluted $1: 2$ with DMSO to produce 12 final concentrations ranging from 0.084 to $173.6 \mathrm{ng} \cdot \mathrm{ml}^{-1}$. Subsequently, $12 \mu \mathrm{l}$ of the stock solution were mixed with $150 \mu \mathrm{l}$ of $2 \%$ Bacto agar. After solidification of the agar, $10 \mu \mathrm{l}$ of eggs in a $0.3 \mathrm{mg} \cdot \mathrm{ml}^{-1}$ solution of amphotericin B (final number of eggs per well was 50-80) were mixed with $10 \mu \mathrm{l}$ of yeast extract and then added to the agar. Only DMSO (1.3\%) was used in the control wells. Yeast extract was prepared as described by Hubert and Kerboeuf [21] ( $1 \mathrm{~g}$ of yeast extract in $90 \mathrm{ml}$ of $0.85 \% \mathrm{NaCl}$ was autoclaved for $20 \mathrm{~min}$, and then $27 \mathrm{ml}$ of this solution were mixed with $3 \mathrm{ml}$ of $10 \times$ concentrated Earle's solution). The plates were incubated for seven days at $25^{\circ} \mathrm{C}$. Larvae were then killed with Lugol's iodine solution, and the number of third-stage (L3) larvae at each concentration was determined under an inverted stereomicroscope. The L3 larvae were morphologically differentiated and identified as by Van Wyk et al. [22].

\section{Results}

\section{Egg hatch discrimination dose test}

We examined 27 sheep farms in 2011-2012 in six districts of Slovakia for BZ resistance in gastrointestinal nematodes. Table 1 shows the percentages of hatched eggs for the farms obtained by the EHDDT. Instead of using the conventional threshold values $\left(\mathrm{ED}_{50}\right.$ or $\mathrm{ED}_{99}$ ), we used the

\section{Table 1 Number of sheep farms with different percentage levels of hatched eggs at a threshold DD of $0.1 \mathrm{ug} \cdot \mathrm{ml}^{-1}$} TBZ in EHDDTs on 27 farms

Percentage of hatched eggs at a DD of $0.1 \mathrm{ug} \cdot \mathrm{ml}^{-1} \mathrm{TBZ}$

$(<10 \%) \quad(10-20 \%) \quad(20-40 \%) \quad(>40 \%)$

$\begin{array}{lllll}\text { \# of farms } & 12 & 10 & 3\end{array}$


number of hatched eggs at a DD concentration of 0.1 ug. $\mathrm{ml}^{-1} \mathrm{TBZ}$, because the results of Coles et al. [13] and Čudeková et al. [14] suggested that this DD prevented $99 \%$ of the susceptible eggs from hatching. The percentage of hatched eggs is thus a direct measure of the percentage of BZ-resistant eggs in the sample. The percentages were divided into four categories of farms based of their status of susceptibility/resistance determined by hatching in the EHDDT. More than $10 \%$ of the eggs from 12 farms hatched, and $10-20 \%$ of the eggs from 10 farms hatched. The hatching percentages for the DD on three farms were $20-40 \%$. High hatching percentages $(>40 \%)$ were recorded on only two farms.

\section{Micro-agar larval development test}

The results of the MALDTs from 49 farms are presented in Table 2. We chose the threshold discriminating concentration of $21.6 \mathrm{ng} \cdot \mathrm{ml}^{-1}$ IVM aglycone because no development of the susceptible isolates occurred at this concentration $[15,16]$. L3 larvae from 14 farms $(28.57 \%)$ developed in this threshold concentration, which suggested the presence of IVM-resistant nematodes. A low level of resistant parasites ( $<30 \%$ development) was detected on 12 farms (24.49\%). The presence of more than $30 \%$ resistant parasites was confirmed on only two farms (4.08\%). The differentiation of L3 larvae at the discrimination concentrations revealed the presence of Ostertagia/Trichostrongylus spp. in all 14 tests. The MALDT was negative from 32 farms. Data could not be obtained from three farms due to low egg counts.

\section{Discussion}

The first survey of BZ resistance on Slovak sheep farms was conducted in 1991-1993 [9]. This survey examined 77 farms and documented the presence of $\mathrm{BZ}$ resistance on six farms $(7.8 \%)$ by the use of the EHT. A further survey was performed in 2003-2004 [8,10] using in vivo and in vitro tests and found resistance to BZ products on two of 29 farms (6.9\%). The status of BZ resistance on Slovak sheep farms changed little between 1993 and 2006, assuming a low persistent prevalence of BZ resistance during the intervening, untested period.

Our survey of BZ resistance was performed in 20112013, when we examined 27 sheep farms in six districts of Slovakia. We used the EHDDT to determine the percentage of resistant larvae in the populations by using a DD of TBZ $\left(0.1 \mu \mathrm{g} \cdot \mathrm{ml}^{-1}\right)$. We found resistant nematodes on all farms. Three separate field surveys of AR in parasites of sheep farms over almost two decades suggested that the percentage of farms with resistant nematodes was stable below $10 \%$. All three surveys had used different classifications of BZ resistance. The farms in the first survey [9] used the WAAVP classification [20] that defined resistance as $\mathrm{ED}_{50}$ values in the $\mathrm{EHT}$ over $0.1 \mu \mathrm{g} \cdot \mathrm{ml}^{-1} \mathrm{TBZ}$. The second survey $[8,10]$ defined resistance as in vivo FECRs less than 95\% and lower 95\% confidence limits of reduction less than $90 \%$. Additionally, in vitro EHTs and LDTs were used in the survey, and farm populations were classified as resistant if the estimated $\mathrm{ED}_{50}$ was greater than $0.1 \mu \mathrm{g} \cdot \mathrm{ml}^{-1} \mathrm{TBZ}$ in the EHT and if $\mathrm{LC}_{99}$ was over $0.03 \mu \mathrm{g} \cdot \mathrm{ml}^{-1} \mathrm{TBZ}$ in the LDT. The present survey confirmed the presence of $\mathrm{BZ}$ resistant nematodes on all farms. Controversially, the results obtained in 1993 and 2012 are not necessarily different. The majority of the farms in 2013 had hatching percentages below $40 \%$, which estimated $\mathrm{ED}_{50}$ to be below $0.1 \mu \mathrm{g} \cdot \mathrm{ml}^{-1}$ TBZ. Only two of 27 farms (7.4\%) would have exceeded the threshold of $0.1 \mu \mathrm{g} \cdot \mathrm{ml}^{-1} \mathrm{TBZ}$ of the second survey. Based on the questionnaire study of Slovak sheep farms [17], BZs are still in common use, due to the lower price compared to ML drugs. BZs had been widely used on sheep farms in recent decades, which undoubtedly contributed to the development of BZ resistance.

The first report of IVM resistance in Slovakia found resistant nematodes on six of 26 sheep farms (23.08\%) and suspected resistance on eight more farms using in vivo FECRTs [8]. Our survey found a high occurrence ( $>30 \%$ resistant larvae using a DD) of IVM-resistant parasites on two farms (4.35\%) and the presence of low resistance $(<30 \%$ resistant larvae using a DD) on 12 farms (26.07\%). IVM resistance was not detected on 32 of the 46 farms. Čerňanská et al. [8] concluded that the main reason for the unexpectedly high occurrence of IVM resistance on Slovak sheep farms could be due to a lower efficacy of the generic IVM formulations used in the survey. Similarly, van Wyk et al. [23] identified a problem of substandard generic products in South Africa. The occurrence of IVM resistance may thus be lower, as the authors described [8]. BZs and MLs are the most commonly used drugs in Slovakia for drenching sheep. The frequent use of generic IVM formulations in Slovakia during the last two decades, due to their low cost, may result in the lower efficacy. A direct comparison between our results and those of previous surveys is not possible due to the different methodologies used. The correlation between in vivo and in vitro tests is not always good. Maharshi et al. [24]

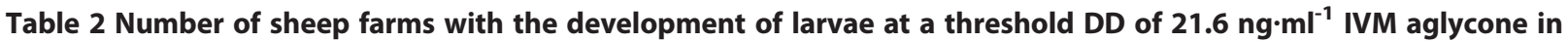
LDTs on 49 farms in Slovakia

\begin{tabular}{cccc}
\hline \# of sheep farms & $\begin{array}{l}\text { Low egg counts } \\
\text { in fecal samples }\end{array}$ & No resistance & $\begin{array}{l}\text { Low resistance } \\
\text { (<30\% development) }\end{array}$ \\
\hline 49 & 3 & 32 & $\begin{array}{l}\text { High resistance } \\
\text { (>30\% development) }\end{array}$ \\
\hline
\end{tabular}


observed a poor correlation between FECRs and the EHT for detecting $\mathrm{BZ}$ resistance. Phenotypic expression in the EHT was evident, with an occurrence of $>30 \%$ homozygous resistant genotypes in the population. Based on our previous studies $[25,14,16]$, the two in vitro tests, EHT and LDT, have the potential to detect a low level of resistance by using the $\mathrm{ED}_{99} / \mathrm{LC}_{99}$ criterion or a $\mathrm{DD}$. The $\mathrm{ED}_{50} / \mathrm{LC}_{50}$ criterion, however, is not able to provide early detection during the development of resistance, especially if the alleles for resistance are rare in the parasite population. Additionally, the in vivo FECR test lacks the sensitivity to detect low levels of resistance [26,27].

The two subclasses of MLs, the avermectins and the milbemycins, are the most commonly used drugs against gastrointestinal parasites in small ruminants in most countries. These drugs entered the anthelmintic market in the 1980s, and IVM-resistant strains of gastrointestinal parasites of sheep have since emerged in many parts of the world. The situation in other European countries is similar to that in Slovakia, where the problem of IVM resistance has not yet reached a critical level. Documented cases of IVM resistance demonstrate that the situation is similar to the status in countries such Australia, New Zealand and South Africa 10-15 years ago. These countries are currently fighting the extreme spread of IVM-resistant parasites on sheep farms, but the reliance on a new anthelmintic class (e.g. aminoacetonitrile derivatives) is not always a solution [28]. All available measures must be used to prevent a repetition of history and to guard against the spread of IVMresistant strains on sheep farms.

Diagnostic tests should be simple and inexpensive, provide rapid and reliable results and be suitable for standardization among the laboratories of many countries [16]. Both versions of the in vitro tests we applied for surveying field resistance provided easy, sensitive, rapid, inexpensive and repeatable diagnostic tools for diagnosing BZ and IVM resistance in the gastrointestinal parasites of sheep. The discriminating doses we used in our study offer valuable information for reducing the effort needed to determine the presence of resistance in parasite populations.

\section{Conclusions}

Both the BZ and IVM surveys indicated that resistance against BZ and ML anthelmintics was present on Slovak sheep farms. Resistance against the BZ class of anthelmintics had been stable for two decades, but a slight increase on IVM resistance was confirmed. Farmers must thus observe the preventive measures to avoid a faster onset of IVM resistance, otherwise the presence of resistant parasites and ineffective treatment may harm the economy of their farms.

\section{Competing interests}

The authors declare that they have no competing interests.

\section{Authors' contributions}

MV planned, designed and initiated the study. MD, OI, AK and MV participated in the experimental field and laboratory work. MD and MV wrote the manuscript and revised it. All authors contributed to the critical revision and approved the final version of the manuscript.

\section{Acknowledgements}

This study was supported by the VEGA grant agency, grant No. 2/0151/13 of the Scientific Agency of the Slovak Academy of Sciences and by Slovak Research and Development Agency project No. LPP - 0186-07 and 0539-10.

\section{Author details}

${ }^{1}$ Institute of Parasitology, Slovak Academy of Sciences, Hlinkova 3, Košice 040 01, Slovak Republic. ${ }^{2}$ Institute of Animal Physiology, Slovak Academy of Sciences, Šoltésovej 4-6, Košice 04001, Slovak Republic.

Received: 15 June 2014 Accepted: 22 September 2014

Published online: 01 October 2014

\section{References}

1. Kaplan RM: Drug resistance in nematodes of veterinary importance: a status report. Trends Parasitol 2004, 20:477-481.

2. Papadopoulos E: Anthelmintic resistance in sheep nematodes. Small Rumin Res 2008, 76:99-103.

3. Geurden $T$, Hoste $H$, Jacquiet $P$, Traversa D, Sotiraki S, Frangipane Di Regalbono A, Tzanidakis N, Kostopoulou D, Gaillac C, Privat S, Giangaspero A, Zanardello C, Noé L, Vanimisetti B, Bartram D: Anthelmintic resistance and multidrug resistance in sheep gastro-intestinal nematodes in France, Greece and Italy. Vet Parasitol 2014, 201:59-66.

4. Papadopoulos E, Himonas CH, Coles GC: Drought and flock isolation may enhance the development of anthelmintic resistance in nematodes. Vet Parasitol 2001, 97:253-259.

5. MA Á-S, Pérez - García J, Cruz - Rojo MA, Rojo - Vázquez FA: Anthelmintic resistance in trichostrongylid nematodes of sheep farms in Northwest Spain. Parasitol Res 2003, 99:78-83.

6. Höglund J, Gustafsson K, Ljungström BL, Engström A, Donnan A, Skuce P: Anthelmintic resistance in Swedish sheep flocks based on a comparison of the results from the faecal egg count reduction test and resistant allele frequencies of the $\beta$ - tubulin gene. Vet Parasitol 2009, 161:60-68.

7. Rinaldi L, Morgan ER, Bosco A, Coles GC, Cringoli G: The maintenance of anthelmintic efficacy in sheep in a Mediterranean climate. Vet Parasitol 2014, 203:139-143.

8. Čerňanská D, Várady M, Čorba J: A survey on anthelmintic resistance in nematode parasites of sheep in the Slovak Republic. Vet Parasito/ 2006, 135:39-45.

9. Praslička J, Várady M, Čorba J, Veselý L: A survey of anthelmintic resistance in Slovakia. Vet Parasitol 1994, 52:169-171.

10. Várady $M$, Čerňanská $D$, Čorba J: Use of two in vitro methods for the detection of anthelmintic resistant nematode parasites on Slovak sheep farms. Vet Parasitol 2006, 135:325-331.

11. Várady $M$, Čorba J: Comparison of six in vitro tests in determining benzimidazole and levamisole resistance in Haemonchus contortus and Ostertagia circumcincta of sheep. Vet Parasitol 1999, 80:239-249.

12. Taylor MA, Hunt KR, Goodyear KL: Anthelmintic resistance detection methods. Vet Parasitol 2002, 103:183-194.

13. Coles GC, Jackson F, Pomroy WE, Prichard RK, Von Samson-Himmelstjerna G Silvestre A, Taylor MA, Vercruysse J: The detection of anthelmintic resistance in nematodes of veterinary importance. Vet Parasitol 2006, 31:167-185.

14. Čudeková P, Várady M, Dolinská M, Königová A: Phenotypic and genotypic characterisation of benzimidazole susceptible and resistant isolates of Haemonchus contortus. Vet Parasitol 2010, 172:155-159.

15. Dolinská $M$, Königová $A$, Várady $M$ : Is the micro-agar larval development test reliable enough to detect ivermectin resistance? Parasitol Res 2012, 111:2201-2204.

16. Dolinská M, Königová A, Letková V, Molnár L, Várady M: Detection of ivermectin resistance by a larval development test - Back to the past or step forward? Vet Parasitol 2013, 198:154-158. 
17. Čerňanská D, Várady M, Čudeková P, Čorba J: Worm control practices on sheep farms in the Slovak Republic. Vet Parasitol 2008, 154:270-276.

18. Hunt KR, Taylor MA: Use of the egg hatch assay on sheep faecal samples for the detection of benzimidazole resistant nematodes. Vet Rec 1989, 125:153-154.

19. Ministry of Agriculture, Fisheries and Food: Manual of Veterinary Parasitological Laboratory Techniques. London: Reference Book 418; 1986.

20. Coles G, Bauer C, Borgsteede FHM, Geerts S, Klei TR, Taylor MA, Waller PJ: World association for the advancement of veterinary parasitology (W.A.A.V.P.) methods for the detection of anthelmintic resistance in nematodes of veterinary importance. Vet Parasitol 1992, 44:35-44.

21. Hubert J, Kerbouf D: A new method for culture of larvae used in diagnosis of ruminant gastrointestinal strongylosis: comparison with faecal cultures. Can J Comp Med 1984, 48:63-71.

22. Van Wyk JA, Cabaret J, Michael LM: Morphological identification of nematode larvae of small ruminants and cattle simplified. Vet Parasitol 2004, 119:277-306.

23. Van Wyk JA, Malan FS, Van Rensburg LJ, Oberem PT, Allan MJ: Quality control in generic anthelmintics: is it adequate? Vet Parasitol 1997, 72:157-165.

24. Maharshi AK, Swarnkar CP, Singh D, Manohar GS, Ayub M: Status of anthelmintic resistance in gastrointestinal nematodes of sheep in Rajasthan. Indian J Anim Sci 2011, 81:105-109.

25. Várady M, Čudeková P, Čorba J: In vitro detection of benzimidazole resistance in Haemonchus contortus: egg hatch test versus larval development test. Vet Parasitol 2007, 149:104-110.

26. Martin PJ, Anderson N, Jarrett RG: Detecting benzimidazole resistance with faecal egg count reduction tests and in vitro assays. Aust Vet J 1989, 66:236-240

27. Várady M, Königová A, Dolinská M, Skolníková E: The in vitro and in vivo response of Haemonchus contortus to benzimidazole treatment: sheep versus goats. In International Conference of the World Association for the Advancement of Veterinary Parasitology: 25-29 August 2013; Perth, Australia; 2013:435.

28. Scott I, Pomroy WE, Kenyon PR, Smith G, Adlington B, Moss A: Lack of efficacy of monepantel against Teladorsagia circumcincta and Trichostrongylus colubriformis. Vet Parasitol 2013, 198:166-171.

doi:10.1186/s12917-014-0233-4

Cite this article as: Dolinská et al: Anthelmintic resistance in sheep gastrointestinal nematodes in Slovakia detected by in-vitro methods. BMC Veterinary Research 2014 10:233.

\section{Submit your next manuscript to BioMed Central and take full advantage of:}

- Convenient online submission

- Thorough peer review

- No space constraints or color figure charges

- Immediate publication on acceptance

- Inclusion in PubMed, CAS, Scopus and Google Scholar

- Research which is freely available for redistribution 